\title{
Application Elimination Et Choix Traduisant La REalité (ELECTRE) On Decission Support System
}

\author{
Agusta Praba Ristadi Pinem ${ }^{1}$, Prind Triajeng Pungkasanti ${ }^{2}$ \\ ${ }^{1}$ Fakultas Teknologi Informasi dan Komunikasi, Universitas Semarang \\ e-mail : agusta.pinem@usm.ac.id \\ ${ }^{2}$ Fakultas Teknologi Informasi dan Komunikasi, Universitas Semarang \\ e-mail : prind@usm.ac.id
}

\section{ARTICLE INFO}

Article history:

Received 04 December 2017

Received in revised form 05 December

2017

Accepted 11 December 2017

Available online 25 January 2018

\begin{abstract}
Technology as a learning material will impact students impact in the future, in certain and details lesson material. Decission Support System teach how to solve the problems with algorythm methods application. One of them is ELimination Et Choix Traduisant la REalité (ELECTRE). ELECTRE is a complex methods with various stages in solving problems. ELECTRE is difficult to understand in convensional way. Furthermore, this research aimed to solve the problems by create experimental tool called ELECTRE application.
\end{abstract}

Keywords: ELimination Et Choix Traduisant la REalité (ELECTRE), Decission Support System

\section{Pendahuluan}

Pemanfaatan teknologi informasi dewasa ini tidak hanya digunakan sebagai alat bantu dalam menyelesaikan permasalahan operasional organisasi tetapi juga digunakan sebagai media bahan ajar. Media bahan ajar yang menggunakan pemanfaatan teknologi sangat berdampak positif terhadap hasil pemahaman mahasiswa kareana dapat menampilkan output dan informasi yang lebih mudah dipahami oleh mahasiswa terutama pada matakuliah yang membutuhkan tingkat pemahaman yang mendalam.

Salah satu mata kuliah yang memiliki tingkat kesulitan yang tinggi dan membutuhkan pemahaman yang mendalam adalah matakuliah Sistem Pendukung Keputusan (SPK). Matakuliah SPK menerapkan metode algoritma dalam penyelesaian masalah suatu kasus. Ada beberapa metode algoritma yang dapat diterapkan dalam penyelesaian masalah SPK, salah satunya adalah algoritma ELimination Et Choix Traduisant la REalité (ELECTRE).

ELECTRE merupakan metode algoritma yang memiliki banyak tahapan untuk hasil akhirnya, karena ELECTRE merupakan metode yang digunakan untuk proses perangkingan atau memilih alternatif terbaik yang berdasarkan pada hubungan outranking dan menggunakan indeks kesesuaian dan ketidaksesuaian untuk menganalisa hubungan antar alternatif (Sevkli, 2010). Alternatif sendiri yaitu calon variable yang nantinya akan dipilih dan diurutkan berdasarkan nilai kriteria atau atribut. Suatu alternatif dikatakan mendominasi alternatif yang lainnya jika satu atau lebih kriterianya melebihi (dibandingkan dengan kriteria dari alternatif lain) dan sama dengan kriteria lain yang tersisa (Kusumadewi dkk., 2006)

Proses perhitungan dengan menggunakan algoritma ELECTRE yang memiliki banyak tahapan membuat mahasiswa merasa kesulitan dalam memahami tahapan ELECTRE apabila penjelasan metode ini hanya menggunakan penjelasan secara konvensional. Oleh sebab itu, peneliti membuat Aplikasi ELimination Et Choix Traduisant la REalité (ELECTRE) pada Sistem Pendukung Keputusan, diharapkan aplikasi bahan ajar ini dapat membantu dan memudahkan mahasiswa 
mengerti dan memahami penerapan ELECTRE dalam penyelesaian masalah dan menghasilkan informasi sebagai pendukung keputusan suatu kasus.

\section{Landasan Teori}

\subsection{Sistem Pendukung Keputusan (SPK)}

Sistem pendukung keputusan (SPK) adalah sebuah sistem yang dapat membantu seseorang dalam mengambil keputusan dari berbagai jenis pilihan yang dilakukan secara akurat dan sesuai dengan sasaran yang diinginkan (Faisal dan Permana, 2015). Ada beberapa karakteristik dalam SPK menurut Gholam dkk (2005), yaitu:

a. SPK menawarkan keluwesan, kemudahan beradaptasi, dan tanggapan yang cepat.

b. Memungkinkan pemakai memulai dan mengendalikan masukan dan keluaran.

c. Dapat dioperasikan dengan sedikit atau tanpa bantuan pemrograman professional.

d. Menyediakan dukungan untuk keputusan dan permasalahan yang solusinya tidak dapat ditentukan di depan.

e. Menggunakan analisis data dan perangkat pemodelan yang canggih.

Sedangkan tujuan dari SPK, yaitu (Laudon dan Laudon, 1998):

a. Membantu menyelesaikan masalah semi-terstruktur.

b. Mendukung manajer dalam mengambil keputusan.

c. Meningkatkan efektifitas bukan efisiensi pengambilan keputusan.

Jadi dapat dikatakan bahwa SPK dapat memberikan manfaat bagi pengambil keputusan dalam meningkatkan efektifitas dan efisiensi kerja terutama dalam proses pengambilan keputusan.

\subsection{Et Choix Traduisant la REalité (ELECTRE)}

MCDM (Multi Criteria Decision Making) merupakan salah satu metode sistem pendukung keputusan (Hadiguna dkk., 2014). MCDM dapat digunakan untuk permasalahan yang memiliki banyak kriteria dalam menentukan solusi dengan memilih alternatif terbaik dan ELECTRE merupakan salah satu metode yang termasuk dalam MCDM (Gholam dkk., 2009). Pada MCDM terdapat dua pengelompokkan lebih spesifik lagi, yaitu MADM (Multi Attribute Decision Making) dan MODM (Multi Objective Decision Making). Metode MADM dapat menemukan alternatif yang paling sesuai dengan melakukan perangkingan terhadap alternatif dengan mengacu pada atribut, bobot dan perhitungan perbandingan antar alternatif terhadap atributnya masingmasing (Lavasani dkk., 2012). ELECTRE termasuk dalam kelompok MADM dengan model normalisasi (Mardani dkk., 2015).

ELECTRE merupakan metode yang digunakan untuk proses perangkingan atau memilih alternatif terbaik yang berdasarkan pada hubungan outranking dan menggunakan indeks kesesuaian dan ketidaksesuaian untuk menganalisa hubungan antar alternatif (Sevkli, 2010). Indeks kesesuaian dan ketidaksesuaian dapat dihitung atau dinyatakan sebagai tingkat kepuasan pengambil keputusan terhadap alternatif satu dengan yang lainnya (Sevkli, 2010). Metode ELECTRE didasarkan pada konsep perangkingan melalui perbandingan berpasangan antar alternatif pada kriteria yang sesuai. Suatu alternatif dikatakan mendominasi alternatif yang lainnya jika satu atau lebih kriterianya melebihi (dibandingkan dengan kriteria dari alternatif lain) dan sama dengan kriteria lain yang tersisa (Kusumadewi dkk., 2006).

a) Langkah-langkah dalam ELECTRE

Berikut ini adalah enam langkah metode ELECTRE:

Langkah 1: Data atau kriteria dan sub kriteria dinormalisasi dengan tujuan untuk dapat dikomparasi. Setiap normalisasi dapat dilakukan dengan persamaan (Rumus 1):

$$
R_{i j}=\frac{x_{i j}}{\sqrt{\sum_{i=1}^{m} x_{i j}^{2}}} \text {, untuk } 1,2,3, \ldots . . \mathrm{m} \text { dan } \mathrm{j}=1,2,3, \ldots \ldots . \mathrm{n} \text { (Rumus } 1 \text { ) }
$$

Langkah 2: Mencari nilai dari rata-rata nilai dengan menggunakan rata-rata geometrik karena memberikan kemudahan dan konsistensi dalam mengambil nilai dari himpunan (Kaya dan Kahraman, 2011).

$$
G=\sqrt[n]{x_{1} \cdot x_{2} \cdot x_{3} \ldots x_{n}} \quad \text { (Rumus 2) }
$$


Dimana $\mathrm{n}$ adalah jumlah sub kriteria dalam satu kriteria dan $\mathrm{x}$ adalah nilainya. Kemudian diperoleh matriks $\mathrm{R}$ hasil normalisasi dan rata-rata dari sub kriteria yang membentuk perbandingan berpasangan setiap alternatif di setiap kriteria.

$$
R=\left[\begin{array}{lll}
r_{11} & r_{12} & r_{1 j} \\
r_{21} & r_{22} & r_{2 j} \\
r_{i 1} & r_{i 2} & r_{i j}
\end{array}\right] \quad \text { (Rumus 3) }
$$

Langkah 3: Mencari matrix bobot ternormalisasi.

$R$ adalah matriks yang telah di normalisasi dimana i menyatakan alternatif, $\mathrm{j}$ menyatakan kriteria dan $r_{i j}$ adalah normalisasi pengukuran pilihan alternatif ke-i dalam hubungannya dengan kriteria ke-j. Kemudian matriks $R$ dikalikan dengan bobot masing-masing kriteria $w_{j}$.

$$
R W=\left[\begin{array}{lll}
w_{1} r_{11} & w_{2} r_{12} & w_{j} r_{1 j} \\
w_{1} r_{21} & w_{2} r_{22} & w_{j} r_{2 j} \\
w_{1} r_{i 1} & w_{2} r_{i 2} & w_{j} r_{i j}
\end{array}\right] \quad \text { (Rumus 4) }
$$

Langkah 4: Menentukan indeks kesesuaian (concordance index) dan ketidaksesuaian (discordance index). Kriteria dalam suatu alternatif termasuk kesesuaian dinyatakan dengan persamaan.

$$
C_{k l}=\left\{j, y_{k j}>y_{i j}\right\}, \text { untuk j }=1,2,3, \ldots, \mathrm{n} \quad \text { (Rumus 5) }
$$

Sebaliknya termasuk dalam ketidaksesuaian apabila

$$
D_{k l}=\left\{j, y_{k j}<y_{i j}\right\} \text {, untuk } \mathrm{j}=1,2,3, \ldots, \mathrm{n} \quad \text { (Rumus 6) }
$$

Langkah 5: Menghitung nilai kesesuaian dan ketidaksesuaian tiap alternatif. Untuk menentukan nilai kesesuaian adalah dengan menjumlahkan bobot-bobot yang termasuk dalam subset kesesuaian.

$$
C_{k l}=\sum_{j \in C_{w}} w_{j} \quad \text { (Rumus 7) }
$$

Untuk menentukan nilai ketidaksesuaian adalah dengan menjumlahkan bobot yang termasuk pada subset ketidaksesuaian.

$$
D_{k l}=\sum_{j \in D_{w}} w_{j} \quad \text { (Rumus 8) }
$$

Langkah 6: Mencari nilai dominan. Nilai Concordance dikurangi dengan Nilai Discordance untuk memperoleh nilai $E^{*}$ atau nilai dominan. Nilai dominan $\left(E^{\prime}\right)$ merupakan patokan rangking pada metode ELECTRE untuk memperoleh keputusan terbaik.

$$
E=C_{k l}-D_{k l} \quad \text { (Rumus 9) }
$$

\section{Hasil dan Pembahasan}

\subsection{Desain Sistem}

Berikut desain sistem menggunakan use case diagram pada gambar 1 yang menggambarkan fungsionalitas sistem secara garis besar. 


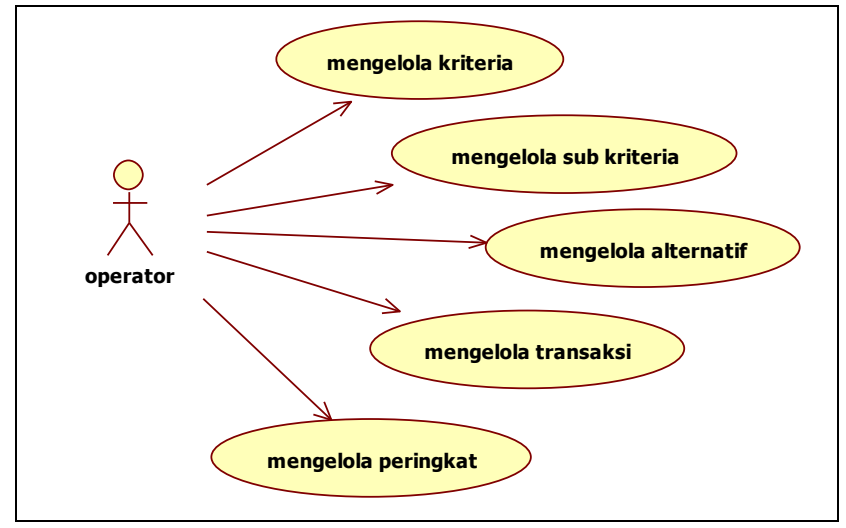

Gambar 1. Use Case Diagram

Use Case Diagram menggambarkan kemampuan sistem dan hak akses pengguna secara umum. Operator selaku pengguna sistem dapat mengelola data alternative, sub kriteria, kriteria dan data transaksi. Data transaksi terkait nilai masing-masing sub kriteria di setiap alternative. Class diagram pada gambar 2 yang menggambarkan struktur data secara umum sistem.

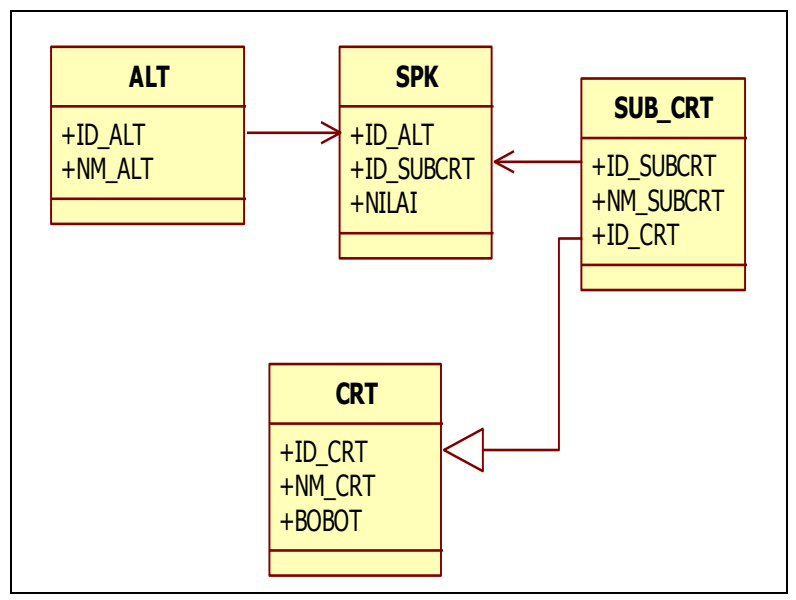

Gambar 2 Class Diagram

Terdapat 4 tabel, tiga sebagai tabel master dan satu sebagai tabel transaksi:

1. Tabel ALT menampung data alternative

2. Tabel SUB_CRT menampung data sub kriteria

3. Tabel CRT menampung data kriteria

Tabel SPK, menjadi tabel transaksi yang berfungsi untuk menampung data nilai setiap alternative untuk masing-masing sub kriteria dan kriterianya.

\subsection{Struktur Tabel}

Setiap tabel pada desain basisdata kemudian diimplementasikan ke dalan DBMS. Struktur tabel merupakan implementasi class diagram kedalam bentuk tabel pada basisdat. Berikut struktur tabel yang diimplementasikan ke dalam DBMS. Sturktur tabel pada gambar 3 telah diimplementasikan di DBMS, selanjutnya adalah memasukan data percobaan, yaitu data fiktif yang digunakan untuk menguji perhitungan pada sisi sistem dengan membandingkan perhitungan menggunakan Ms Excel. Berikut data yang dimasukan kedalam DBMS. 


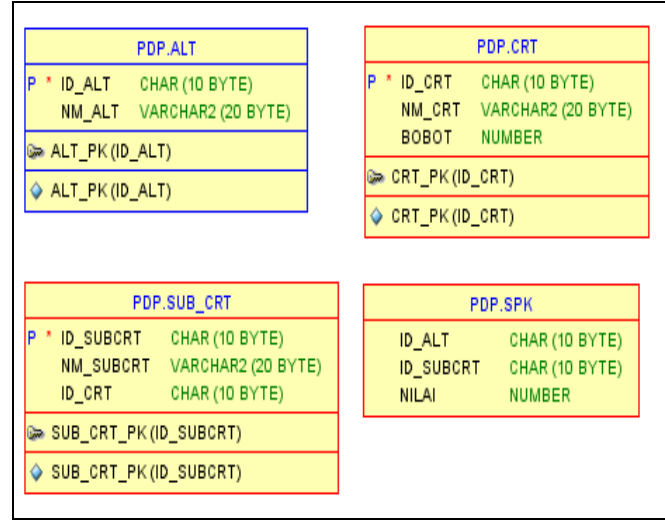

Gambar 3 Struktur Tabel

\subsection{Perhitungan Manual}

Perhitungan manual merupakan tahapan untuk menguji algoritma yang diterapkan pada source code sudah sesuai dengan perhitungan metode ELECTRE. Hasil perhitungan manual akan dibandingkan dengan hasil keluaran dari aplikasi untuk menguji proses aplikasi. Tahapan perhitungan manual dimulai dari penyederhanaan data transaksi di basisdata kedalam bentuk matriks.

Tabel 1 Matriks Nilai Sub Kriteria

\begin{tabular}{crrrrrrrrrrr}
\hline ID_AL & \multicolumn{10}{c}{ SUB KRITERIA } \\
\cline { 2 - 13 } & SC001 & SC00 & SC00 & SC00 & SC00 & SC00 & SC00 & SC00 & SC00 & SC01 \\
A001 & & 2 & 3 & 4 & 5 & 6 & 7 & 8 & 9 & 0 \\
A002 & 6 & 7 & 8 & 6 & 5 & 6 & 4 & 1 & 2 & 4 \\
A003 & 8 & 6 & 4 & 4 & 7 & 5 & 7 & 7 & 4 & 8 \\
A004 & 5 & 5 & 5 & 7 & 3 & 5 & 6 & 5 & 6 & 4 \\
A005 & 8 & 7 & 6 & 5 & 7 & 7 & 7 & 4 & 6 & 6 \\
\hline
\end{tabular}

Tabel 1 merupakan matriks nilai sub kriteria masing-masing alternative. Setiap alternative memiliki 10 sub kriteria berikut nilainya. Matriks pada tabel 1 kemudian dinormalisasi dengan menggunakan persamaan 2. Setiap nilai sub kriteria pada masing-masing alternative dinormalisasi untuk menghilangkan jarak nilai yang terlalu jauh pada sub kriteria yang lain.

Matriks kriteria ternormalisasi kemudian dikalikan dengan bobot setiap kriteria pada. Sehingga menghasilkan matriks bobot ternormalisasi dengan menggunakan persamaan 4. Berikut tabel matriks bobot ternormalisasi.

Tabel 2 Matriks bobot ternormalisasi

\begin{tabular}{cccccc}
\hline \multirow{2}{*}{ ID_ALT } & \multicolumn{5}{c}{ KRITERIA } \\
& $\mathrm{C} 001$ & $\mathrm{C} 002$ & $\mathrm{C} 003$ & $\mathrm{C} 004$ & $\mathrm{C} 005$ \\
\hline $\mathrm{A} 001$ & 0.480 & 1.144 & 0.473 & 0.613 & 0.362 \\
$\mathrm{~A} 002$ & 0.380 & 1.402 & 0.884 & 0.707 & 0.606 \\
$\mathrm{~A} 003$ & 0.439 & 1.498 & 0.836 & 1.146 & 0.281 \\
$\mathrm{~A} 004$ & 0.410 & 1.280 & 0.819 & 0.969 & 0.525 \\
$\mathrm{~A} 005$ & 0.480 & 1.144 & 0.819 & 0.750 & 0.362 \\
\hline
\end{tabular}

Tabel 5.8 atau matriks bobot ternormalisasi merupakan matriks yang digunakan dalam metode ELECTRE. Proses selanjutnya adalah mencari nilai indeks kesesuaian dan ketidaksesuaian dengan menggunakan persamaan 5 dan 6 . Indeks kesesuaian dan ketidaksesuaian 
diperoleh dengan membandingkan masing-masing nilai kriteria pada setiap alternative. Berikut nilai kesesuaian, ketidaksesuaian dan nilai dominan masing-masing alternative.

Tabel 3 Nilai Dominan

\begin{tabular}{llll}
\hline ID_ALT & NILAI C & NILAI D & Nilai Dominan \\
\hline A001 & 9 & 27 & -18 \\
A002 & 23 & 13 & 10 \\
A003 & 28 & 8 & 20 \\
A004 & 20 & 16 & 4 \\
A005 & 17 & 19 & -2 \\
\hline
\end{tabular}

Nilai dominan diperoleh berdasarkan selisih nilai kesesuaian dan ketidaksesuaian. Alternative yang memiliki dominan tertinggi adalah alternative terbaik. Selanjutnya hasil perhitungan manual digunakan sebagai acuan pengujian pada aplikasi berbasis web.

Data pada pengujian kemudian juga dimasukan kedalam basisdata dan dilakukan pengujian untuk melihat kesesuaian hasil perhitungan metode ELECTRE di aplikasi web dan perhitungan di MsExcel. Hasil perhitungan matrik bobot ternormalsasi ditunjukan pada gambar 4. Hasil perhitungan manual kemudian dibandingkan dengan hasil di basisdata. Proses perhitungan matriks bobot ternormailisai di aplikasi maupun perhitungan mempunyai hasil yang sama. Dapat dilihat pada gambar 4.dan tabel 2. Nilai matriks bobot ternormalisasi semua baris data telah sesuai dengan hasil perhitungan manual. Hal ini menunjukan proses normalisasi dan geom mean telah sesuai sebelum masuk pada perhitungan ELECTRE. Selanjutnya metode ELECTRE diimplementasikan kedalam bahasa pemrograman $p h p$.

\begin{tabular}{|c|c|c|c|c|}
\hline ID Alternatif & ID Kriteria & Bobot & Normalisasi & Normalisasi Terbobot \\
\hline $\mathrm{A} 001$ & $\mathrm{C} 001$ & 1 & 0.4804 & 0.4804 \\
\hline $\mathrm{A} 001$ & $\mathrm{COO2}$ & 3 & 0.3815 & 1.1445 \\
\hline $\mathrm{A} 001$ & $\mathrm{C} 003$ & 2 & 0.2364 & 0.4728 \\
\hline $\mathrm{A} 001$ & $\mathrm{COO4}$ & 2 & 0.3063 & 0.6126 \\
\hline $\mathrm{A} 001$ & $\mathrm{CO05}$ & 1 & 0.3622 & 0.3622 \\
\hline $\mathrm{A} 002$ & $\mathrm{C} 001$ & 1 & 0.3798 & 0.3798 \\
\hline $\mathrm{A} 002$ & $\mathrm{C} 002$ & 3 & 0.4672 & 1.4016 \\
\hline $\mathrm{A} 002$ & $\mathrm{CO03}$ & 2 & 0.4422 & 0.8844 \\
\hline $\mathrm{A} 002$ & $\mathrm{COO4}$ & 2 & 0.3537 & 0.7074 \\
\hline $\mathrm{A} 002$ & $\mathrm{C} 005$ & 1 & 0.6061 & 0.6061 \\
\hline $\mathrm{A} 003$ & $\mathrm{C} 001$ & 1 & 0.4385 & 0.4385 \\
\hline $\mathrm{A} 003$ & $\mathrm{C} 002$ & 3 & 0.4995 & 1.4985 \\
\hline $\mathrm{A} 003$ & $\mathrm{COO3}$ & 2 & 0.4179 & 0.8358 \\
\hline $\mathrm{A} 003$ & $\mathrm{COO4}$ & 2 & 0.5730 & 1.1460 \\
\hline $\mathrm{A} 003$ & $\mathrm{CO05}$ & 1 & 0.2806 & 0.2806 \\
\hline $\mathrm{A} 004$ & $\mathrm{C} 001$ & 1 & 0.4102 & 0.4102 \\
\hline A004 & $\mathrm{COO2}$ & 3 & 0.4265 & 1.2795 \\
\hline A004 & $\mathrm{C} 003$ & 2 & 0.4094 & 0.8188 \\
\hline $\mathrm{A} 004$ & $\mathrm{COO4}$ & 2 & 0.4843 & 0.9686 \\
\hline A004 & $\mathrm{C} 005$ & 1 & 0.5249 & 0.5249 \\
\hline $\mathrm{A} 005$ & $\mathrm{C} 001$ & 1 & 0.4804 & 0.4804 \\
\hline $\mathrm{A} 005$ & $\mathrm{COO2}$ & 3 & 0.3815 & 1.1445 \\
\hline $\mathrm{A} 005$ & $\mathrm{C} 003$ & 2 & 0.4094 & 0.8188 \\
\hline A005 & $\mathrm{COO} 4$ & 2 & 0.3751 & 0.7502 \\
\hline
\end{tabular}

Gambar 4. Hasil matriks bobot ternormalisasi di aplikasi 
Model Sistem Pendukung Keputusan menggunakan Metode ELECTRE

\begin{tabular}{|c|c|c|c|}
\hline Nama Alternatif & Nilai C & Nilai D & Nilai C-D \\
\hline ALT 3 & 28 & 8 & 20 \\
\hline ALT 2 & 23 & 13 & 4 \\
\hline ALT 4 & 20 & 16 & -2 \\
\hline ALT 5 & 17 & 19 & -18 \\
\hline ALT 1 & 9 & 27 & 4 \\
\hline
\end{tabular}

Gambar 5. Hasil perangkingan pada sistem

Gambar 5. merupakan hasil perhitungan nilai dominan dari sistem, yaitu dengan membandingkan nilai kesesuaian dan ketidakkesesuaian setiap alternatif. Nilai dominan digunakan sebagai nila acuan perangkingan. Pada gambar 6 menunjukan nilai dominan yang sama dengan hasil perhitungan manual pada tabel 3. Hal ini menunjukan proses algoritma pada metode ELECTRE yang diimplementasikan kedalam bahasa pemrograman telah sesuai. Pengujian telah dilakukan dengan membandingkan hasil perhitungan manual setiap proses menghasilkan nilai yang sama dengan hasil perhitungan aplikasi berbasis web yang dibangun. Selanjutnya aplikasi web metode ELECTRE dapat diterapkan dalam berbagai kasus pada sistem pendukung keputusan.

\section{Kesimpulan}

Kesimpulan dari penelitian ini adalah :

1. Aplikasi ELECTRE telah berhasil dibangun dan telah sesuai dengan tahapan pada metode yang ditunjukan dengan hasil pengujian perhitungan manual dengan perhitungan sistem.

2. Hasil dari aplikasi ELECTRE ini merupakan media bantu pembelajaran bagi mahasiswa dalam memahami tahapan proses yang dilakukan oleh metode ELECTRE dalam menyelesaikan masalah dalam pengambilan keputusan.

3. Aplikasi ELECTRE ini sudah bersifat dinamis, sehingga jumlah kriteria, sub kriteri, bobot dan alternative dapat ditambah atau dikurangi sesuai dengan kasus yang diujikan.

\section{Daftar Pustaka}

[1] Bonczek, Robert H.. Foundations of Decision Support Systems, Elsevier Science \& Technology Books xvii, 393 pages. 1981

[2] Faisal dan Permana, S.D. Sistem Penunjang Keputusan Pemilihan Sekolah Menengah Kejuruan Teknik Komputer Dan Jaringan Yang Terfavorit Dengan Menggunakan MultiCriteria Decision Making, Jurnal Teknologi Informasi dan Ilmu Komputer (JTIIK), Vol. 2, No. 1, hlm. 11-19. April 2015

[3] Gholam, A.M., Saremi, H.Q., dan Ramezani, M. Design A New Mixed Expert Decision Aiding System Using Fuzzy Electre III Method For Vendor Selection, Expert Systems with Applications 3 , 10837-10847. 2009

[4] Hadiguna, R.A., Kamil, I., dan Delati, A.Implementing A Web Based Decision Support System for Disaster Logistics: A Case Study of An Evacuation Location Assessment for Indonesia. International Journal of Disaster Risk Reduction 9, 38-47. 2014

[5] Kaya, T., dan Kahraman, C. An Integrated Fuzzy AHP-ELECTRE Methodology For Environmental Impact Assessment, Expert Systems with Applications 38, 8553-8562. 2011

[6] Kusumadewi, S., Hartati, S., Harjoko, A., dan Wardoyo, R. Fuzzy Multi-Attribute Decision Making, Graha Ilmu, Yogyakarta. 2006

[7] Laudon, K. C., dan Laudon, J. P. Management Information Systems New Approaches to Organization \& Technology, 5th Edition, Prentice Hall International. Inc. 1998 
[8] Lavasani, S.M.M., Wang, J., Yang, Z., dan Finlay, J.Application of MADM in a Fuzzy Environment For Selecting The Best Barrier For Offshore Wells, Expert Systems with Applications 39, 2466-2478. 2012

[9] Mardani, A., Jusoh, A., dan Zavadskas, E.K. Fuzzy Multiple Criteria Decision-Making Techniques and Applications - Two Decades Review From 1994 to 2014, Expert Systems with Applications 42, 4126-4148. 2015

[10] Sevkli, M. An Application of The Fuzzy ELECTRE Method For Supplier Selection, International Journal of Production Research 48, 3393-3405. 2010

[11] Turban, E., dkk. Decision Support System and Intelligent Systems (Sistem Pendukung Keputusan dan Sistem Cerdas), Edisi 7 Jilid 1, Andi, Yogyakarta. 2005 